Sakarya Üniversitesi İlahiyat Fakültesi Dergisi

Journal of Sakarya University Faculty of Theology

ISSN: 2146-9806 I e-ISSN: 1304-6535

Cilt/Volume: 23, Say1/Issue: 43, Y11/Year: 2021 (Haziran/June)

Jon Hoover. Ibn Taymiyya. London: Oneworld Academic, 2019, $1 \mathrm{x}+164 \mathrm{~s}$.

\title{
Değerlendiren/Reviewed by
}

\section{Zeynep Yücedoğru}

Dr. Öğr. Üyesi, Bülent Ecevit Üniversitesi İlahiyat Fakültesi, Dinler Tarihi Ana Bilim Dalı - Dr., Bulent Ecevit University Faculty of Theology, Department of History of Religions

z.yucedogru@beun.edu.tr

https://orcid.org/0000-0003-4931-6148

\section{Makale Bilgisi - Article Information}

Makale Türü/Article Type: Kitap Dergerlendirmesi/Book Review

Geliş Tarihi/Date Received: 02/02/2021

Kabul Tarihi/Date Accepted: 24/05/2021

Yayın Tarihi/Date Published: 15/06/2021

İntihal: Bu makale, iThenticate yazılımı ile taranmış ve intihal tespit edilmemiştir. Plagiarism: This article has been scanned by iThenticate and no plagiarism detected.

Copyright $($ P Published by Sakarya Üniversitesi İlahiyat Fakültesi - Sakarya University Faculty of Theology, Sakarya/Turkey. 


\section{Jon Hoover. Ibn Taymiyya. London: Oneworld Academic, 2019, IX+164 s.}

Yaşadığı zamanın ve bundan yüzyıllar sonraki modern dönemin şüphesiz en meşhur ve en tartışmalı isimlerinden/figürlerinden biri Hanbelî alim İbn Teymiyye'dir (ö. 1328). 14. yüzyıl İslam dünyasının temel meselelerine dair sayısız fetva kaleme almış ve usûlü'd-dîn, fıkıh, hadis, tefsir gibi birçok ilmin aslî konularını kapsayan hacimli eserler yazmıştır. İbn Teymiyye'nin hem entelektüel ve ilmî duruşuna hem de serdettiği görüşlere dair ilk olarak zikredilmesi gerekenlerden biri onun zamanın genel kabul gören dini inanç ve pratiklerinin neredeyse tamamına muhalif oluşudur. Döneminin ana akım görüşlerine şiddetle muhalefet etmesi sebebiyle Şam zindanlarında birçok kere mahkûmiyeti tecrübe etmiş ve yine zindanda kalemi ve mürekkebi tükendikten kısa bir süre sonra vefat etmiştir. Bu muhalif duruş kendisinden sonraki zamana da sirayet etmiş İbn Teymiyye'nin fikirleri bir yandan çok eleştirilmiş bir yandan ise aşırı uç olarak tanımlanabilecek birçok dinî ve siyasî grup tarafından benimsenmiştir. Buna benzer zıt bir eğilim İbn Teymiyye ile ilgili akademik literatürde de kendini göstermiş özellikle de Batı'da yapılan çalışmalarda bir grup araştırmacı onu yeterli ilmî derinliğe sahip olmayan "literalist" bir İslâmî figür olarak sunarken diğer grup daha mutedil bir yaklaşım benimsemiş ve onun entelektüel mirasını ve düşünce dünyasını anlamak amacıyla eserlerini incelemiştir. Değerlendirmemize konu olan kitap ikinci gruba dahildir.

Mevzubahis eser, Oneworld yayıncılığın Müslüman alim, şair, sanatkâr, bilim adamı ve siyası-dinî figürleri hakkında genel okuyucu kitlesini hedef alan "Makers of the Muslim World" serisinden çıkmıştır. "İslam dünyasının" bugünkü haline gelmesinde katkısı olan meşhur isimleri modern okuyucuya tanıtmayı amaçlayan bu seriye İbn Teymiyye çalışmalarının öne çıkan ismi olan yazar Dr. Jon Hoover elimizdeki eserle katkıda bulunmuştur. İbn Teymiyye'ye dair yapılan son çalışmalardan hareketle onun hayatı ve düşüncesi üzerinden ilmî dünyasına dair genel ama kapsayıcı ve doğru bir bilgi sunma amacıyla kaleme alınmıştır. Kitabın temel argümanı, İbn Teymiyye'ye dair bugüne kadar yapılmış çalışmaları sentezleyen, giriş mahiyetinde ve temel hususları da kapsayan ilk akademik eser olmasıdır. Kitabın ilk iki bölümü İbn Teymiyye'nin hayatının önemli olaylarını aktarmakta ve belli başlı eserlerinden bazılarını özellikle Moğol istilalarına denk gelen birkaç risalesini düşüncesine uygun olarak tarihlendirmektedir. Sonraki altı bölüm ise konularına göre İbn Teymiyye'nin düşüncesini belirli başlıklar altında ele almaktadır.

İbn Teymiyye'nin düşünce ve yazılarında öne çıkan hususlar, usûli'd-dîn ve uygulamalarda görülen bidat saydığı yeniliklere karşı çıkması, İslam'ın temel kaynaklarına reformist yaklaşımı, Şi 'îliğe ve Hıristiyanlığa karşı Sünniliğin savunuculuğu yapması ve vahyin akla ters düşmediğinin apolojetik izâhıdır. Bu mükerrer hususların eserin içeriğinde de öne çıktığını görüyoruz. Bu 
hususlara ek olarak yazarın vurguladığı bir diğer nokta ise İbn Teymiyye'nin hangi konuyu ele aldığı fark etmeksizin yazılarında baskın olan ütiliteryan yaklaşımın incelediğimiz bu eserde öne çıkarılmaya gayret edildiğidir.

Keskin ifadeleri, sıra dışı görüşleri ve ekstrem yorumları sebebiyle İbn Teymiyye'nin karakteri ve ruh sağlığı zaman zaman akademik çalışmalara konu olmuştur. ${ }^{1}$ Hoover, bu algıya, ilk iki bölümde sunduğu İbn Teymiyye biyografisi ile farklı bir perspektif sunmaya çalışır. İbn Teymiyye'nin çalkantılı hayatının tüm yönleri ilmî kariyerinin teşekkülü aşamalarına referansla aktarılmış ve içinde bulunduğu sosyo-politik şartların düşünce dünyasına etkisinin ortaya konulması amaçlanmıştır. Bu vaâdin iki kısa kitap bölümün el verdiği ölçüde yerine getirildiği görülmektedir. İbn Teymiyye'nin hayatı hakkında en fazla bilgiyi edindiğimiz kaynak olan ez-Zehebî, İbn Teymiyye'nin karakter ve insanî ilişkilerine ilişkin tezat bir portre çizer. Zaman zaman kaba bazen de nazik bir tutum sergileyen İbn Teymiyye kimseye boyun eğmeyen, ibadet ehli, giyimde itidal üzere ve dünyalığa ilgisi olmayan bir âlim olarak resmedilmiştir.

Moğol istilalarının ortasında çalkantılı bir sosyal ortamda çocukluk ve gençlik dönemi geçiren İbn Teymiyye'nin ilmî kariyerinin ilk döneminde baskın olan iki husus vardır: Moğollara karşı fetvaları ve Eş arî geleneğe eleştirisi. İbn Teymiyye'ye göre Müslüman olmalarına rağmen din üzere olmayan Moğollar İslam'ın her türlü meselesinin önüne kendi menfaatlerini geçirmişlerdir ve bu nedenle onlara karşı cihat şarttır. Eş'arîler'e ise ilahî sıfatlar konusunda eleştiriler kaleme almış, neticesinde tecsîm suçlamasıyla defalarca yargılanmışıı. İlmî kariyerinin ikinci safhasında ise İslamî gruplara olan eleştirisi keskinleşir çünkü İslam dininin bidatvârî dinî ritüeller ve uydurulan pratikler sonucu tedrici bir şekilde muharref bir form aldığına kanaat eder. Yazar, bu kanaatin İbn Teymiyye'nin bundan sonraki ilmî kariyerini bütünüyle şekillendirdiğini öne sürmektedir. Dönemin ana akım Sufî ve kelam ekollerini hayatının son dönemlerine kadar sert bir şekilde eleştirmeye devam eder. İbn Teymiyye, bu keskin ihtilafa ek olarak üç talak ve kabir ziyareti hakkındaki sıra dışı görüşleri nedeniyle de ömrünün son yıllarında birkaç kez daha mahkûm edilir. Yazar, İbn Teymiyye'nin bu eleştirel yaklaşımının "farklı yönlerde tüm (ilmî) kariyerinin Allah adına yapılan bir cihat" olarak yorumlanabileceğini belirtir (s. 38).

Kitabın üçüncü bölümünde İbn Teymiyye' nin teolojisinde ibadetin üstünlüğünü ele alınırken dördüncüsünde ibadet anlayışı fıkıh ve bidat kavramları eşliğinde analiz edilmektedir. En sarih ifadesiyle, İbn Teymiyye'ye göre ibadet, Allah'ın irade ettiği şekilde ve vahyettiği hukuk üzere/gereğince sadece O'na kulluk etmektir. Yazar, optimizm olarak tanımladığı bir yaklaşımla İbn

1 D. P. Little, “Did Ibn Taymiyya Have a Screw Loose?”, Studia Islamica 41 (1975), 93-111. 
Teymiyye'nin ibadeti insan fitratında yerleşik bir unsur olarak gördüğünü belirtir. Diğer bir ifadeyle, insan Allah'1 sevmek ve sadece ona ibadet etmek üzere yaratılmıştır. Yazara göre, İbn Teymiyye bu noktada akıl ve vahyin birbirini tamamladığı iddiası gibi insan fıtratı ile Peygamber'in öğretisinin de birbirini tamamlayıp mükemmelleştirdiğini savunur. Yukarıda bahsi geçtiği gibi kitabın dördüncü bölümü İbn Teymiyye'ye göre ibadetin mahiyetini konusunu irdeler. Yazarın temel yaklaşımı, İbn Teymiyye'nin konuya ilişkin fıkhî-teolojik perspektifini öne çıkarmaktır. İbadet sadece belirli bir kuralı olan bir dinî pratik değil Allah'ın sevdiğini sevmek, yasakladığından kaçınmak ve emrettiğine uymak gibi geniş bir anlama sahiptir. Dinî pratiklerde yenilikleri kabul etmeyen İbn Teymiyye'ye göre ibadetin mahiyeti vahyedilmiş hukuk ile temellendirilmelidir. Burada İbn Teymiyye'nin fıkhı, vahyedilmiş ve uydurulmuş olmak üzere iki kategoriye ayırdığını ve fıkhî hüküm olarak irade edilen değişikliklere şiddetle karşı çıktığını görmekteyiz. Sufî grupların sem'a ve zikr gibi pratiklerini ve musiki için kullanılan müzik aletlerini bidat kabul etmekte ve vahyî temelleri olmadığını savunmaktadır. İbn Teymiyye' nin bu eleştirisinin temelinde onun her hükmü Kur'an ve Hadis metinlerine dayandırma ihtiyacı yatmaktadır ki bu ona çok da haklı olmayan "metinci" (textualist) nitelemesinin yakıştırılmasına neden olmuştur. Bunun aslında indirgemeci bir yaklaşım olduğunu belirtmek gerekir. Zira İbn Teymiyye hükümleri mutlaka bir metne dayandırma prensibine paralel olarak maslahatı da gözetir. Ona göre, Sufîlerin ibadet şeklinin dine bir faydası olup olmadığı sorgulanmalı ve şeriatın maslahatı asla göz ardı etmeyeceği unutulmamalıdır. Yazar, İbn Teymiyye'nin bu düşüncesini etik bir ruhîlik (spiritual) anlayışı olarak yorumlar. Haddizatında, İbn Teymiyye'ye göre Sufî bir yola intisabın ve dinî pratiklerinin amacı mistik bir tecrübe değil Allah'ın hükümlerine eksizsiz bir şekilde teslim olmaktır. Burada İbn Teymiyye'nin temel endişesi Müslüman toplumda hızla zuhur eden yeni dinî inanç ve pratikleri dinin aslî kaynaklarını merkeze ala alarak değerlendirmek ve bunların dinin aslına dahil edilmesinin önüne geçmektir.

Kitabın beşinci bölümde yazar, İbn Teymiyye'nin fikhî otoriteyi ve Allah'ın şeriatını nasıl anladı̆̆ı üzerine yoğunlaşır. İbn Teymiyye, Sufî ve kelam ekollerine karşı dile getirdiği eleştirinin bir benzerini fıkıh ekollerine de yöneltir. Ona göre, dört büyük fıkhî mezhep bağımsız aklın bir ürünüdür ve nihaî otorite değildir. Zamanının dört fıkhî mezhebinin hükümleri doğrudan Kur'an ve Sünnet yerine kendi mezheplerinin önceki görüşlerine dayandırmasına tepki olarak İbn Teymiyye Kur'an'ın şeriatın kaynaklarını yeni bir epistemolojik-hiyerarşik sıralamaya tabi tutar. Burada amacı genel kabul gören fikhî konformizmi (uyumculuk) karşı çıkmak ve Kur'an ile Sünnet'in üstünlüğünü vurgulamaktır. Ona göre dinin fikhî otoritesinin kaynağı Kur'an, Sünnet, icma ve kıyastır. İbn Teymiyye bazı fakihlerin farklı fıkhî meselelerde 
orta yolu bulmak adına icma ve kıyası Kur'an ve Sünnet'e rağmen kabul ettiklerini iddia eder ve bunu şu zeminde eleştirir: Doğru bir kıyas ve sahih icma asla kitâbî metin ile çelişmez; bir ihtilaf varsa şayet geçerli bir kıyas değildir. Benzer bir şekilde icma da yeni bir fıkhî kural çıkarmaz sadece Peygamberin öğretisini açıklar ve Kur'an'a veya Sünnet'e ihtilaf etmez. Hoover, İbn Teymiyye'nin bu yaklaşımını geniş ilmî düşüncesinin ve dinin apolojisinin fikıh alanındaki yansımaları olarak yorumlar (s. 77).

Hoover, İbn Teymiyye'nin düşüncesinin ağırlıklı olarak ütiliteryan bir akıl yürütmeye dayandığını iddia etmekte ve yukarıda da değinildiği gibi onun düşüncesini tematik bir yaklaşımla sunarken bu faydacı anlayışını öne çıkarmayı çalışmaktadır. Bunu en belirgin olarak eserin altıncı bölümünde İbn Teymiyye'nin sosyal etik anlayışının izah edildiği kısımda görmekteyiz. İbn Teymiyye' nin sosyal etik prensibinin temelinde "iyiliği emretmek, kötülükten nehyetmek" (Kur'an 3/104, 7/157, 9/71) yer almaktadır. Ona göre bu prensibin hem teoride hem fiiliyatta tam anlamıyla karşılığını veren cihattır. Burada İbn Teymiyye'nin cihat kavramına çok geniş bir anlam yüklediğini sadece inanmayanlara karşı yürütülen mücadelenin çok ötesinde bir mana atfedildiğini görüyoruz. Her ne kadar İbn Teymiyye için cihadı yönlendiren temel prensip şeriatı yani "vahyedilmiş hukuku" takip etmek olsa da bu, her yanlış duruma güçlü bir mukavemet göstermek demek değil aksine öncelikli olarak azami faydayı gözetmektir. İbn Teymiyye'ye göre etik açıdan bir müphemlikle karşılaşıldığında şeriatın emri uygulanırken fayda-zarar dengesi gözetilmeli şayet şeriatın uygulanmasının getireceği yarar bir miktar zarara sebebiyet verecek olsa bile emredilmelidir. Fayda ve zararın birbirine eşit olduğu, doğru ile yanlışın iç içe geçtiği durumlarda ise ne nehyedilir ne de emredilir. İbn Teymiyye için sosyal düzen ve siyasi sorumluluk dinin parçasıdır. Sosyal ve siyasi alanı yönlendiren de fayda ve zararın ütiliteryan bir hesaplaması olmalıdır. Sosyal düzenin bekasını her şeyden önemli gören İbn Teymiyye'ye göre "Adaletsiz bir hükümdarın altmış yılı hükümdarsız tek bir geceden evladir." 2

Gerek din gerekse usûlü'd-dîne dair İbn Teymiyye'nin temel endişesi Kur'an ve Sünnet'e geri dönülmesi ve sonradan ilave olduğunu düşündüğü her türlü unsurun bu zeminde sorgulanmasıdır. Onun muhalifliğinin temelinde bu endişe yer almaktadır. Yine bu endişeden hareketle, en belirgin yönelimlerinden biri teoloji hakkında yazılar kaleme almaktır. Hoover'ın bize aktardığına göre, bu temayül İbn Teymiyye'ye sorulduğunda "teolojik/kelâmî konuların felsefe ve tasavvuf etkileşimi sonucu aslından uzaklaştığını ve bu konuları gereksiz ilavelerden arındırmak ve aklî ve naklî argümanları sağlamanın görevini” olduğunu belirtir (s. 107). Kitabın yedinci bölümü

2 İbn Teymiyye, Mecmu 'atü'l- Fetâvâ, nşr. Abdurrahman ibn Muhammed Kasım, Muhammed ibn Abdurrahman ibn Muhammed (Riyad: Metâbi'ür-Riyâd, 1961-1967) 20/54, 91. 
bu argümanları belirli konular bağlamında sunmaktadır. Temel mesele genelde Allah'ın yarattığı dünya ve varlıklarla olan ilişkisini nasıl anlamak gerektiği özelde ise "arşa istiva" gibi antropomorfik ifadeleri nasıl yorumlamak gerektiğidir. İbn Teymiyye'ye göre, Allah kendisini Kur'an'da nasıl tanımladıysa öyle tanımlamak fakat bu ifadelerin Allah'ın yarattıkları için kullanıldığında aynı anlamı ifade etmediğini bilmek gerekmektedir. Allah'ın antropomorfik ifadelerden tamamen soyutlanması veya bu ifadelerin tevil edilmesini veya anlamlarının bilinmediğinin tasdiki gibi görüşlere karşı çıkan İbn Teymiyye antropomorfik ifadelerin sadece lafızlarının değil anlamlarının da Peygamber tarafından açıklandığını ve sahabe ve tabiûn üzerinden nakledildiğini savunmaktadır. Ona göre, tecsîmi çağrıştıran bu ifadelerin lafızlarını ve anlamlarını bilirken mahiyetini bilmemekteyiz. Burada İbn Teymiyye'nin temel amacının teolojik-fıkhî bir endişe ile Allah hakkındaki dili ve terminolojiyi sahihleştirmek, Peygamberin vahyin bilgisine sahip olduğunu ve bize aktarmış olduğunu inkâr etmemek olduğunu belirtebiliriz. Bu amaç, İbn Teymiyye'nin düşüncesinin temel unsurlardan biridir.

Kitabın son kısmı olan sekizinci bölümünde ilahî adalet, yani kötülük ve teodise problemine İbn Teymiyye'nin nasıl yaklaştı̆̆ı özetlenmektedir. Allah'ın yarattıkları ile olan ilişkisine etik bir mahiyet de nispet eden İbn Teymiyye' ye göre Allah salt kötülük yaratmamakta aksine irade ettiği her şeyde "iyi olması bakımından hikmetli bir amaç bulunmaktadır." Gazzâlı̂' den esinlendiği düşünülen İbn Teymiyye'ye göre "mümkünatta, var olandan daha iyi hiçbir şey yoktur" (s. 127). Ona göre, var olandan daha farklı bir dünya yaratmaya kadir olan Allah bu dünyayı yaratmıştır zira mümkün olan, olabilecek arasında en iyisi budur. Hoover, İ̉bn Teymiyye'nin kötülüğü temelde bir ilahî terbiye meselesi olarak gördüğünü ifade etmektedir. Bununla birlikte yazar, İbn Teymiyye'nin kötülüğün yaratılmasındaki ilahî hikmeti zaman zaman sorgulanamaz olarak nitelediğine bazen ise hiçbir açıklama getirmeden konuyu es geçtiğine dikkat çekmektedir. Eserin son konusu olan teodise, Peygamberlerin günah ve hatadan masum olması, sahih peygamberin özellikleri, tahrif edilmiş bir din olarak Hıristiyanlığın Müslümanlara bir ders niteliğinde olması, kafirlerin nihaî sonu ve cennet-cehennemin ebediliği konuları eşliğinde incelenmiştir. Hoover bu geniş analiz sonucunda İbn Teymiyye'nin etik yaklaşımını hem Yaratıcı hem de yaratılmışlar bağlamında dinin hizmetine adanmış bir ütiliteryanizm olarak tanımlar. İnsanlar dinî hukukun gelişimi için fayda-zarar dengesi gözetmeliyken Yüce Yaratıcı kullarının sahih kulluğu oranınca azami faydayı yaratan, irade ve emredendir. İbn Teymiyye düşüncesinin etik ve kulluk (worship) anlayışına Allah'ın şeriatına tam bir teslimiyeti gözeterek ağırlık verdiğini ifade eden Hoover, “İbn Teymiyye'nin Allah'ının, çok büyük bir çoğunluk için mümkün olan azami faydayı yaratan kozmik bir ütiliteryan" olduğunu iddia eder (s. 139). Yazara göre, İbn Tey- 
miyye'nin teoloji ile iştigali sadece teorik mahiyette bir gayret olmayıp noksansız bir itaat ve kulluğa götüren bir pratiktir. İbn Teymiyye'nin ilmî çabası Allah'a kulluğun mahiyetini belirleyen ve bunu rasyonelleştiren fikhî-teolojik bir girişim olarak tanımlanmıştır. Bu kanaât sadece Hoover'a has değildir. İbn Teymiyye'ye dair benzer bir minvalde akademik çalışmalar yürüten modern araştırmacıların çoğu onun ilmî düşüncesinin temel çerçevesini fikhî-teolojik bir nitelikte olduğu konusunda fikir birliği içerisindedirler.

Yazarın eser boyunca öne çıkan "tasvir edici" yaklaşımı bölümlerin tamaminda neredeyse hiç değişmemiş, konular sistematik bir çerçevede, gereksiz detaylara yer vermeden fakat bütüncül bir bakış açısıyla ele alınmıştır. Her bölümün sonunda özet mahiyetindeki kısımlarda yazar analizlerini kısaca sunmuş fakat görüş belirtmekten kaçınmıştır. Yazar, kitabın başında belirttiği “İbn Teymiyye'nin düşünce dünyasını kendi eserleri ve ikincil literatür üzerinden doğru sunmak" amacına bağlı kalmıştır. Bölüm sonlarındaki kısa özetlerin eserin sonuç bölümü olarak ayrılmış "epilog” kısmında nispeten genişletildiğini görmekteyiz. Çalışma boyunca vurgulanan ve öne çıkarılmaya çalışılan İbn Teymiyye' nin ütiliteryan akıl yürütmesi, sonuç değerlendirmesinin de merkezindedir. Hoover, bu düşüncenin modern zamandaki yansımalarına dikkat çekmek amacıyla iki farklı dinî grubun İbn Teymiyye'nin fetvalarını şiddet ve terör eylemlerini temellendirmek için nasıl kullandığını aktarmaktadır. Yazara göre, el-Kaide terör örgütü lideri Usame bin Ladin Amerika'ya yönelik terör faaliyetleri için İbn Teymiyye'nin Moğollara karşı yazılan fetvalarını kullanırken Mısır asıllı bir diğer dinî grup İslam Cemaati Mısır hükümetine karşı yürüttüğü terör ve şiddet eylemlerini aynı fetvalara dayanarak bu tür faaliyetlerin İslam dinine olan zararının faydasından fazla olduğu gerekçesiyle sonlandırma kararı almıştır. Her iki grubun da İbn Teymiyye'nin ütiliteryan akıl yürütmesine ve yazılarına dayandığını fakat farklı politik realite anlayışının onları zıt sonuçlara ulaştırdı̆̆ına dikkat çekmiştir. Akabinde, İbn Teymiyye' nin düşüncesinin vefatı sonrasında çok da etkili olmadığını fakat öğrencisi İbn Kayyim el-Cevziyye' nin (ö. 1350) onun ilmî mirasını sonraki yüzyıllara aktardığının altı çizilmiştir. Yazar, son olarak İbn Teymiyye'nin düşüncelerinin farklı yüzyıllarda çeşitli akımlar ve gruplarca benimsendiğine ve Eş 'arîliğe, İbnü'l-'Arabî özelinde panteist Sufîliğe, Şi 'iliğe, Hıristiyanlı̆̆a ve türbe dindarlığına yönelttiği eleştirilerinin günümüzde de tesirini devam ettirdiğine dikkat çekmektedir. İslam'ın mahiyeti konusundaki tartışmalarda İbn Teymiyye'nin hala çok etkin bir yeri olduğunu belirten yazar bu vurgu ile mülahazasını sonlandırmaktadır.

Bu eser, İbn Teymiyye'ye dair öne çıkan konuları ve hususları olabilecek en özet haliyle fakat mühim hususları kapsayacak şekilde inceleyen ilk akademik çalışma olması hasebiyle alana ilgi duyan araştırmacılar ve öğrenciler için başvuru kitabı niteliğindedir. Konular teknik derinliğe inilmeden genel okuyucuya da hitap edilecek şekilde aktarılmıştır. Bu yönden, daha yoğun 
içerik beklentisini tam karşılamamakta fakat yazar eserin önsözünde bu hususa dair bir açıklama yapmaktadır. Üslup ve dil açısından anlaşılır olan eser, tematik olarak İbn Teymiyye' nin muğlak fikirlerini mümkün olan açık haliyle yansıtmak üzere sıralanmıştır. Yazarın İbn Teymiyye düşüncesini tarafsız bir şekilde aktarması ve ideolojik olmayan bir yaklaşımla onun ilmî derinliğini yansıtmaya çalışması hem eserin temelde muhatap aldığı okuyucu kitlesini olabildiğince genişletmekte hem de İbn Teymiyye çalışmaları için temel kaynaklardan biri olma ihtimalini arttırmaktadır.

Son olarak, bu eser İbn Teymiyye'nin düşüncesine dair farklı bakış açılarından olsa dahi genel bir perspektif yansitmaktadır. Bu nedenle, İbn Teymiyye düşüncesinin paradoksal yönlerinin onun ilmî tabiatına mı yoksa düşüncesindeki değişikliklere mi işaret ettiğini söyleyemiyoruz. Fakat burada belirtilmesi gereken husus bu durumun incelediğimiz çalışmanın niteliği ile ilgili değil aksine İbn Teymiyye çalışmalarının henüz o geniş perspektifi yansıtabilecek bir noktaya varmamış olmasından kaynaklanmaktadır. Bu noktaya varma yolunda Hoover'ın çalışması önemli bir basamak olarak değerlendirilebilir. 